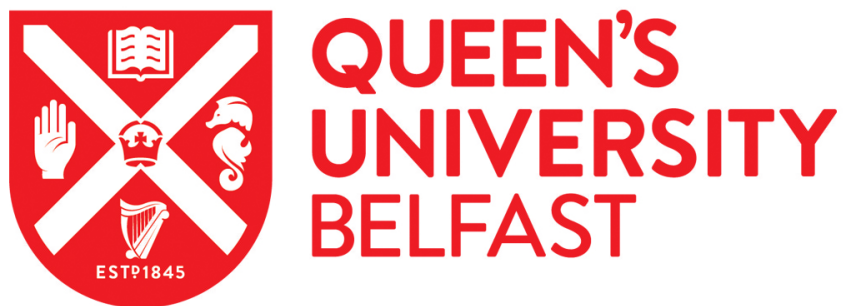

\section{A new model to predict diffusive self-heating during composting incorporating the reaction engineering approach (REA) framework}

Putranto, A., \& Chen, X. D. (2017). A new model to predict diffusive self-heating during composting incorporating the reaction engineering approach (REA) framework. Bioresource Technology, 232, 211-221.

https://doi.org/10.1016/j.biortech.2017.01.065

Published in:

Bioresource Technology

Document Version:

Peer reviewed version

Queen's University Belfast - Research Portal:

Link to publication record in Queen's University Belfast Research Portal

Publisher rights

(c) 2017 Elsevier Ltd. This manuscript version is made available under the CC-BY-NC-ND 4.0 license http://creativecommons.org/licenses/by$\mathrm{nc}-\mathrm{nd} / 4.0 /$,which permits distribution and reproduction for non-commercial purposes, provided the author and source are cited.

\section{General rights}

Copyright for the publications made accessible via the Queen's University Belfast Research Portal is retained by the author(s) and / or other copyright owners and it is a condition of accessing these publications that users recognise and abide by the legal requirements associated with these rights.

Take down policy

The Research Portal is Queen's institutional repository that provides access to Queen's research output. Every effort has been made to ensure that content in the Research Portal does not infringe any person's rights, or applicable UK laws. If you discover content in the Research Portal that you believe breaches copyright or violates any law, please contact openaccess@qub.ac.uk. 
A new model to predict diffusive self-heating during composting incorporatingthe reaction engineering approach (REA) framework

$$
\text { Aditya Putranto }{ }^{1,2}, \text { Xiao Dong Chen }{ }^{1 *}
$$

${ }^{1}$ School of Chemical and Environmental Engineering, College of Chemical Engineering, Chemistry and Material Science, Soochow University, Suzhou, Jiangsu Province, PR China ${ }^{2}$ School of Chemistry and Chemical Engineering, Queen’s University Belfast, David Keir Building, Stranmillis Road, Belfast BT9 5AG, UK 


\begin{abstract}
During composting, self-heating may occur due to the exothermicities of the chemical and biological reactions. An accurate model for predicting maximum temperature is useful in predicting whether the phenomena would occur and to what extent it would have undergone. Elevated temperatures would lead to undesirable situations such as the release of large amount of toxic gases or sometimes would even lead to spontaneous combustion. In this paper, we report a new model for predicting the profiles of temperature, concentration of oxygen, moisture content and concentration of water vapor during composting. The model, which consists of a set of equations of conservation of heat and mass transfer as well as biological heating term, employs the reaction engineering approach (REA) framework to describe the local evaporation/condensation rate quantitatively. A good agreement between the predicted and experimental data of temperature during composting of sewage sludge is observed. The modeling indicates that the maximum temperature is achieved after some 46 weeks of composting. Following this period, the temperature decreases in line with a significant decrease in moisture content and a tremendous increase in concentration of water vapor, indicating the massive cooling effect due to water evaporation. The spatial profiles indicate that the maximum temperature is approximately located at the middle-bottom of the compost piles. Towards the upper surface of the piles, the moisture content and concentration of water vapor decreases due to the moisture transfer to the surrounding. The newly proposed model can be used as reliable simulation tool to explore several geometry configurations and operating conditions for avoiding elevated temperature build-up and self-heating during industrial composting.
\end{abstract}


Key words: reaction engineering approach (REA), model, composting, evaporation/condensation, self-heating

*Corresponding author’s email: xdchen@mail.suda.edu.cn

\section{Introduction}

Composting is an effective process to convert organic solid waste materials into stable organic components under controlled conditions (Rynk, 1992). Since it can improve the land use and decrease carbon emissions, it is considered as a sustainable strategy to maintain agricultural ecosystems (Jiang et al, 2015). Microorganisms play an important role in degradation of the solid waste and their survivals are affected by physical and chemical conditions (Wang et al, 2015). Ambient temperature, moisture content, concentration of oxygen inside the compost piles and carbon to nitrogen ratio $(\mathrm{C} / \mathrm{N})$ are the primary factors that influence composting (Ahn et al, 2008). For sewage sludge composting, aeration rate influences nitrogen stability, maturity and gas emissions. On the other hand, $\mathrm{pH}$ and germination rate are only slightly altered by the aeration rate (Yuan et al, 2016). During sewage sludge composting, the addition of carbon sources reduces the nitrogen loss and therefore increase the compost quality. This may be because of improved population of bacteria involved in nitrification (Meng et al, 2016). In addition, co-composting of sewage sludge with mushroom substrate and wheat straw assists in reducing ammonia emission due to higher porosity and extra carbon sources. Co-composting sewage sludge with other substrates also increases the compost quality while minimizing ammonia emission (Meng et al, 2017). 
Generally, composting can be divided into four stages (Moraga et al, 2009). In the first stage, the temperature increases due to the growth of aerobic microorganisms. The respiration releases heat which increases the pile temperature. Due to the temperature rise, the aerobic microorganisms are replaced by the thermophilic microorganisms which can survive under elevated temperature. This stage is also marked by the temperature rise due to cellulose oxidation from the substrate. Since the oxidation continues to occur, a significant temperature rise may occur which leads to self-heating. At this stage, the liberated heat by oxidation is much higher than the released heat to the surrounding. This is further followed up by the temperature decrease because of the depletion of oxygen inside the piles (Moraga et al, 2009).

In aerobic composting, cellulose oxidation and biological activity are responsible for determining the temperature rise during the process. It is likely that at the beginning of composting, the biological activity is dominated by the aerobic microorganisms while at the elevated temperature, they are replaced by the thermophilic ones (Luangwilai et al, 2010). As a result of these two exothermic reactions, internal heating inside the compost piles may occur. When the heat released by the process is much larger that the heat absorbed by the environment, self-ignition may occur (Sexton et al, 2001). The operating conditions seem to play an important role of self-heating during composting (Moraga et al, 2009). The height of compost piles may affect the extent of self-heating since it is related to the ratio of volume per unit surface area. The higher ratio of the volume per unit surface area accelerates the self-heating (Moraga et al, 2009). The ambient temperature and wind velocity are also reported to affect the extent of self-heating. The lower ambient temperature minimizes the self-heating effects since it increases the dissipated heat to the environment. Similarly, the wind velocity provides cooling effects to the 
compost piles (Moraga et al, 2009). Rynk et al (2000) further predicted that moisture content inside compost piles higher than $45 \%$ deters the extent of self-heating because the heat generated is used for water evaporation. If the moisture content inside the pile is below $20 \%$, the activity of microorganisms is retarded which lowers the heat produced (Luangwilai et al, 2010). The moisture content in the range of 20 to $45 \%$ is considered as the critical moisture content leading to spontaneous self-heating (Luangwilai et al, 2010).

Self-ignition due to oxidation presents a serious threat during composting and other industrial processes. Various experimental studies have been undertaken to study the behavior of the thermal ignition (Bowes, 1984; Gray, 1991; Chen et al, 2013). Traditionally, basket-heating method, based on Frank-Kamenetskii method (1939), has been employed (Bowes, 1984; Gray, 1991) but this method is not efficient considering the time and resources needed for experiments. By using the transient method recently, Chen et al (2013) proves that for infinite Biot number, the Frank-Kamenetskii parameters have a linear relationship with the dimensionless crossingpoint temperature (the geometrical centre temperature when the second derivative against distance is zero). On top of experiments, mechanistic mathematical modeling has been undertaken in which a set of equations of conservation was used to predict experimental the thermal explosion of combustible materials (Sexton et al, 2001; Gray et al, 2002). These methodologies cannot be applied to composting as the scale of composting is usually large and the process is slow.

For composting, several mathematical models have been proposed and implemented (Sidhu et al, 2007; Nelson et al, 2007; Moraga et al, 2009). Nelson et al (2007) developed the 
spatially uniform model in which the biological activity was incorporated by implementing the biological reaction rate proposed by Chen and Mitchell (1999). The proposed reaction rate describes both growth and dormant period of the biomass by using both monotonic increasing and decreasing function (Chen and Mitchell, 1996). The self-heating model (Nelson et al, 2007) represented well the generic behaviors during composting and the dependence of the phenomena on the kinetic parameters. Sidhu et al (2007) proposed a spatial mathematical model, which consists of equations of conservation of heat and oxygen to estimate the concentration of oxygen and temperature during diffusive-heating composting. Luangwilai et al (2010) also employed a one-dimensional model to describe composting in a convective system by using equations of conservation of heat and oxygen. The above-mentioned works had not been compared with actual experimental results and did not incorporate water effects.

Although several mathematical models have been proposed and employed, the effects of moisture content have not been included in the modeling. The moisture plays an important role in composting since the relatively low moisture content inhibits the growth of microorganisms but the high moisture content may also not be effective for composting since large amount of heat is used for water evaporation (Rynk et al, 2000; Lin et al, 2008). Moisture content also influences the degradation of soluble organics and hydrolysis of the substrate (Wang et al, 2015). The moisture content of up to $60 \%$ of the compost weight may accelerate the composting process (Nakayama et al, 2007). At higher level of moisture, the anaerobic condition may also occur which leads to severe smells (Cornell Waste Management Institute, 1996). Liang et al (2003) suggested that, a composting process has to be undertaken with moisture contents between 30 and $60 \%$. The moisture content affects the temperature profiles during composting, especially 
when self-heating is involved (Nelson et al, 2006). On the other hand, self-heating in compost may be taken as an advantage as it provides 'free energy' to dewater the compost (a kind of sludge) which is sometimes called bio-drying (Velis et al, 2009; Winkler et al, 2013; Villegas and Huilinir, 2014). In the bio-drying, the metabolic heat is used to evaporate the water from the waste matrix. The final products of bio-drying have high calorific value allowing them for energy generation in external facilities (Winkler et al, 2013). The bio-drying results in final moisture content of 20\%-wt basis (Velis et al, 2009). The airflow rate, initial moisture content and microbial activity affect the kinetics of bio-drying significantly (Velis et al 2009; Villegas and Huilinir, 2014).

Nevertheless, the moisture may be firstly taken as being transferred inside the compost solid matrix by capillary diffusion (as a first approximation). Also, it is also possible that the moisture can migrate from the pore-surface of the porous compost materials (dense solid regions) to the void spaces inside compost piles by local evaporation and condensation schemes, much like what have been described in the drying processes for porous materials (Chen and Putranto, 2013). To the best of our knowledge, there has been no explicit, accurate formulation of the rate of local evaporation/condensation rate presented to investigate the moisture effect upon compost heating (a biologically triggered self-heating process).

The reaction engineering approach (REA) was initially proposed by Professor X.D. Chen in 1996 to model the drying kinetics of thin layer or small size materials (Chen and Putranto, 2013). REA has since been further developed and extended to describe drying and heat/mass transfer processes under various challenging conditions (Putranto et al, 2011 ${ }^{\mathrm{a}, \mathrm{b}}$ ). Recently, REA 
has been applied to model the local evaporation rate inside the materials undergoing heat and mass transfer processes. The combination of the REA with a set of dimensional equations of conservations has yielded the spatial reaction engineering approach (S-REA) (Putranto and Chen, $2013^{\mathrm{a}, \mathrm{b}}$ ). The S-REA models very well the convective drying, intermittent drying, baking, heat treatment of wood and water vapor sorption (Putranto and Chen, 2013ª, 2014ª, 2015

The paper is organized as follows: firstly, the experimental details reported previously are briefly reviewed followed up by the development of mathematical models. The measured results were employed as a benchmark for the current model. Subsequently, the relevant discussions of modeling results are provided.

\section{Experimental details}

The experimental data to validate the modeling are derived from the work of Moraga et al (2009). In order to better understand the modeling framework, the experimental settings are reviewed briefly here. The pile was established from sewage sludge from a municipal waste treatment plant in Santiago, Chile. Based on the sewage sludge produced in July 2004, the pile was built in the third week of February 2005 (Moraga et al, 2009). The pile was established to give trapezoidal configuration with height of $2.5 \mathrm{~m}$, bottom width of $8.5 \mathrm{~m}$ and top width of 2.5 m (refer to Figure 1(a)). During composting, the temperatures were recorded for initial 6 weeks by K-type thermocouples (length of $0.1 \mathrm{~m}$ and diameter of $0.0015 \mathrm{~m}$ ) with flexible stainless steel coating. The measurement system was connected to a programmable computer for data acquisition (Moraga et al, 2009). During the composting, the ambient temperature is around 10 ${ }^{\circ} \mathrm{C}$, concentration of oxygen is $0.272 \mathrm{~kg} \cdot \mathrm{m}^{-3}$, humidity is $0.01 \mathrm{~kg}$ water.kg dry air ${ }^{-1}$ and $\mathrm{C} / \mathrm{N}$ ratio 
of 28. Since the porosity of the sewage sludge packing is very low, the system is treated as a diffusive system.

\section{Mathematical modeling}

In order to describe the spatial profiles of concentration of oxygen, moisture content, concentration of water vapor and temperature inside the composting piles, a set of equations of heat and mass transfer conservations are used. Since the length of composting piles (z-direction) is much higher than the height (x-direction) and depth (y-direction), the mass and heat balances in $x$ and $y$-direction (refer to Figure 1(a)) are developed. Since the packing of the sewage sludge has very low porosity and the packing is placed in a roofed area (where the wind effects are minimum), the convection terms are not incorporated in the modeling.

The mass balance that describes the concentration of oxygen can be written as (Sidhu et al 2007; Nelson, et al, 2007):

$$
\varepsilon \frac{\partial C_{o x}}{\partial t}=D_{e f f, o x}\left(\frac{\partial^{2} C_{o x}}{\partial x^{2}}+\frac{\partial^{2} C_{o x}}{\partial y^{2}}\right)-(1-\varepsilon) A_{c} \rho_{c} C_{o x} \exp \left(\frac{-E_{c}}{R T}\right)
$$

where $C_{o x}$ is the concentration of oxygen inside the piles $\left(\mathrm{kg}^{-3} \mathrm{~m}^{-3}\right), D_{\text {eff,ox }}$ is the diffusivity of oxygen $\left(\mathrm{m}^{2} \cdot \mathrm{s}^{-1}\right), \varepsilon$ is the porosity of the piles, $A_{c}$ is the Arrhenius constant of the cellulose oxidation reaction $\left(\mathrm{m}^{3} \cdot \mathrm{kg}^{-1} \cdot \mathrm{s}^{-1}\right), E_{c}$ is the activation energy of the cellulose oxidation reaction $\left(\mathrm{J}_{\mathrm{mol}}{ }^{-1}\right)$ and $T$ is the temperature inside the piles (K).

The mass balance of liquid water can be expressed as (Putranto and Chen, 2013 ${ }^{\mathrm{a}, \mathrm{b}} ; 2015^{\mathrm{a}, \mathrm{b}}$ ): 


$$
\frac{\partial\left(C_{s} X\right)}{\partial t}=D_{w, l}\left(\frac{\partial^{2}\left(C_{s} X\right)}{\partial x^{2}}+\frac{\partial^{2}\left(C_{s} X\right)}{\partial y^{2}}\right)-\dot{I}
$$

where $X$ is the moisture content inside the piles (kg water.kg dry solids ${ }^{-1}$ ), $D_{w, l}$ is the diffusivity of liquid water $\left(\mathrm{m}^{2} . \mathrm{s}^{-1}\right), C_{s}$ is the solids concentration $\left(\mathrm{kg}\right.$ dry solids. $\left.\mathrm{m}^{-3}\right)$ and $I$ is the local evaporation rate inside the piles $\left(\mathrm{kg}\right.$ water. $\left.\mathrm{m}^{-3} \cdot \mathrm{s}^{-1}\right)$.

While the mass balance of water vapor can be written as (Putranto and Chen, 2013 $\left.2015^{\mathrm{a}, \mathrm{b}}\right)$ :

$$
\varepsilon \frac{\partial C_{v}}{\partial t}=D_{w, v}\left(\frac{\partial^{2} C_{v}}{\partial x^{2}}+\frac{\partial^{2} C_{v}}{\partial y^{2}}\right)+\dot{I}(1-\varepsilon)
$$

where $C_{v}$ is the concentration of water vapor inside the piles $\left(\mathrm{kg}^{-\mathrm{m}^{-3}}\right)$ and $D_{w, v}$ is the diffusivity of water vapor $\left(\mathrm{m}^{2} \cdot \mathrm{s}^{-1}\right)$.

I is the local evaporation rate of the water from the solid matrix of porous compost materials to the void spaces inside the piles. The reaction engineering approach (REA) is implemented here to describe the local evaporation/condensationrate. By using the REA, the local evaporation rate can be expressed as (Putranto and Chen, 2013 ${ }^{\mathrm{a}, \mathrm{b}} ; 2015^{\mathrm{a}, \mathrm{b}}$ ):

$$
\dot{I}=h_{m} A_{i n}\left[C_{v, s a t} \exp \left(\frac{-\Delta E_{v}}{R T}\right)-C_{v}\right]
$$

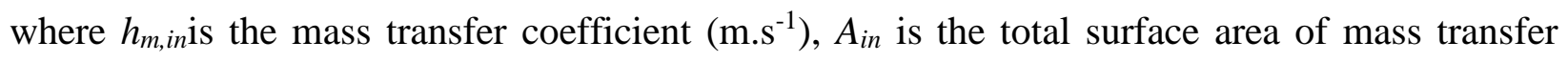
$\left(\mathrm{m}^{2} \cdot \mathrm{m}^{-3}\right), C_{v, \text { sat }}$ is the saturated water vapor concentration $\left(\mathrm{kg} \cdot \mathrm{m}^{-3}\right), \Delta E_{v}$ is the activation energy $\left(\mathrm{J}_{\mathrm{mol}}{ }^{-1}\right)$. The local evaporation rate (I) is used in equations (2) and (3) to link the mass balance of liquid water and water vapor inside the compost piles. 
The review of the reaction engineering approach (REA) has been presented previously (Chen and Putranto, 2013; Putranto and Chen, 2015 a,b) and briefly summarized in Appendix A. The relative activation energy of compost can be written as (Putranto and Chen, 2014 ):

$$
\frac{\Delta E_{v}}{\Delta E_{v, b}}=\left[1+703.336\left(X-X_{b}\right)^{1.291}\right] \exp \left[-8.082\left(X-X_{b}\right)^{0.353}\right]
$$

where $\Delta E_{v, b}$ represents the maximum $\Delta E_{v}$ at the corresponding humidity and temperature (Putranto and Chen, 2013 $\left.3^{\mathrm{a}, \mathrm{b}} ; 2015\right)$. The $\Delta E_{v . b}$ is evaluated using equation (A4). The combination of the relative activation energy (equation (5)) and the equilibrium activation energy yields the activation energy to represent the difficulty to remove the moisture from the solid matrix of the compost piles.

The heat balance of the piles can be represented as (Chen and Mitchell, 1996; Sidhu, et al, 2007; Putranto and Chen, 2013ª, $\left.2015^{\mathrm{a}, \mathrm{b}}\right)$ :

$$
\begin{aligned}
& \rho C_{p} \frac{\partial T}{\partial t}=k\left(\frac{\partial^{2} T}{\partial x^{2}}+\frac{\partial^{2} T}{\partial y^{2}}\right)+Q_{c}(1-\varepsilon) A_{c} \rho_{c} C_{o x} \exp \left(\frac{-E_{c}}{R T}\right) \\
& +Q_{b}(1-\varepsilon) \rho_{b} \rho_{c}\left(\frac{A_{1} \exp \left(\frac{-E_{1}}{R T}\right)}{\left.1+A_{2} \exp \left(\frac{-E_{2}}{R T}\right)\right)-I(1-\varepsilon) \Delta H_{v}}\right.
\end{aligned}
$$

where $\rho$ is the density of the piles $\left(\mathrm{kg} \cdot \mathrm{m}^{-3}\right), C_{p}$ is the specific heat of the piles $\left(\mathrm{J}^{\mathrm{kg}} \mathrm{kg}^{-1} \cdot \mathrm{K}^{-1}\right), T$ is the temperature of the piles $(\mathrm{K}), k$ is the thermal conductivity of the piles $\left(\mathrm{W} \cdot \mathrm{m}^{-1} \cdot \mathrm{K}^{-1}\right), Q_{c}$ is the heat of cellulose oxidation $\left(\mathrm{J} . \mathrm{kg}^{-1}\right), Q_{b}$ is the heat of biomass oxidation $\left(\mathrm{J} \cdot \mathrm{kg}^{-1}\right), \rho_{b}$ is the density of biomass $\left(\mathrm{kg} \cdot \mathrm{m}^{-3}\right), A_{1}$ is the Arrhenius constant of biomass oxidation reaction $\left(\mathrm{m}^{3} \cdot \mathrm{kg}^{-1} \cdot \mathrm{s}^{-1}\right), A_{2}$ is the Arrhenius constant of inhibition of biomass growth, $E_{1}$ is the activation energy of the 
biomass oxidation reaction (J.mol $\left.{ }^{-1}\right)$ and $E_{2}$ is the activation energy of the inhibition growth of biomass ( $\left.\mathrm{J} . \mathrm{mol}^{-1}\right)$ and $\Delta H_{v}$ is the vaporization heat of water $\left(\mathrm{J} \cdot \mathrm{kg}^{-1}\right)$.

The initial conditions of equations (1), (2), (3) and (6) are, respectively $t=0, C_{o x}=C_{o x, 0}, X=X_{0}, C_{v}=C_{v, 0}, T=T_{0}$

Referring to Figure 1(b), the boundary conditions for the equations are:

A, B and C:

$n \nabla .\left(-D_{w} C_{s} X\right)=h_{m} \varepsilon_{w}\left(C_{v, s}-C_{v}\right) \quad$ (convective liquid water transfer)

$n \nabla .\left(-D_{v} C_{v}\right)=h_{m} \varepsilon_{v}\left(C_{v, s}-C_{v}\right) \quad$ (convective water vapor transfer)

$C_{o x}=C_{\infty} \quad$ (ambient oxygen concentration)

$-n \cdot(-k \nabla . T)=h\left(T_{b}-T\right) \quad$ (convective heat transfer)

D:

$n \nabla \cdot\left(-D_{w} C_{s} X\right)=0 \quad$ (no liquid water transfer)

$n \nabla .\left(-D_{v} C_{v}\right)=0 \quad$ (no water vapor transfer)

$n \nabla .\left(D_{o x} C_{o x}\right)=0 \quad$ (no oxygen transfer)

n. $(-k \nabla \cdot T)=0 \quad$ (adiabatic), or

$T=T_{a} \quad$ (ambient temperature)

Two schemes are attempted as the boundary condition at the bottom of the piles. Scheme A implements equations (7) to (14) as the boundary conditions while Scheme B uses equations (7) to (13) and (15) as the boundary conditions. The physical properties used in the modeling are 
presented in Table 1. In order to yield the spatial profiles of concentration of oxygen, moisture content, concentration of water vapor and temperature inside the composting piles during composting, equations (1) to (6) in conjunction with the initial and boundary conditions are solved simultaneously by using finite element solver. The predicted profiles are then validated towards the experimental data of Moraga et al (2009).

\section{Results and Discussion}

\subsection{Validation of results of modeling towards experimental data and the temporal evolution} of temperature, concentration of oxygen, moisture content and concentration of water vapor

Figure 1(c) indicates the results of validation of modeling of temperature inside the piles during initial 6 weeks of composting using the boundary conditions listed in equations (7) to (14).As shown in Figure 1(c), at the pile height of $0.4 \mathrm{~m}$, the predicted temperatures match very well with the experimental data ( $R^{2}$ of 0.99 ). Similarly, the temperatures at the pile height of 2.15 $\mathrm{m}$ are predicted well by this modeling $\left(R^{2}\right.$ of 0.93$)$. Benchmarks against the modeling applied by Moraga et al (2009) show REA framework yields closer agreement towards the experimental data. For the pile height of $2.15 \mathrm{~m}$, the other modeling (Moraga et al, 2009) predicts an increase in the temperature profiles after 5 weeks of composting. Nevertheless, the REA framework estimates well the temperatures during this period well.

For the bottom of the piles, it is also attempted to use ambient temperature as the boundary condition whose results are shown in Figure 1(d). While the REA modeling implementing this boundary condition estimates well the temperature at the pile height of 2.15 
$\mathrm{m}$, the model underestimates the temperature profiles at the pile height of $0.4 \mathrm{~m}$. This underestimation may indicate that this boundary condition is less appropriate than the boundary condition listed in equation (14). The modeling implemented by Sidhu et al (2007) and Moraga et al (2009) also applied the adiabatic boundary condition for the bottom of the piles. In the subsequent section, equation (14) is used as the boundary condition of the pile bottom.

As shown in Figure 2(a), along the compost piles, the temperatures at the pile height of $0.4 \mathrm{~m}$ (point P, refer to Figure 1(a)) are higher than those at the pile height of $2.15 \mathrm{~m}$ (point Q, refer to Figure 1(a)). This may be because the pile height of $0.4 \mathrm{~m}$ is relatively close to the pile base which does not allow the heat exchange to occur. The heat produced by the cellulose oxidation and exothermic biological activity seems to accumulate at this position. During composting, initially, the temperatures rise may be because of the aerobic microorganism growth, represented by the third term of the right hand side of equation (6). This is then further followed by further temperature increase to $385 \mathrm{~K}$ as a result of cellulose oxidation. At this range of temperature, the biological activity seems to be dominated by the thermophilic microorganisms. The cellulose oxidation and the activity of the thermophilic microorganisms are represented by the second and third terms of the right hand side of equation (6), respectively. At $46^{\text {th }}$ week of composting, a significant self-heating was evident by a temperature jump to $514 \mathrm{~K}$. This jump seems to be due to significant increase in the heat generated by cellulose oxidation rate. The heat generated by cellulose oxidation increases to achieve $3970.2 \mathrm{~W} / \mathrm{m}^{3}$ at the $46^{\text {th }}$ week. At this period, it appears that the heat produced by the self-heating process is much larger than the dissipated heat to the surrounding. It is followed by a rapid reduction in temperature due to the exhaustion of oxygen there. After 100 weeks of composting, the heat 
produced by the cellulose oxidation is $0.0221 \mathrm{~W} / \mathrm{m}^{3}$. The temperature profiles at height of $2.15 \mathrm{~m}$ are lower than those at height of 0.4 mwhich could be because of the location of the height of $2.15 \mathrm{~m}$ is close to the upper surface of the pile where the heat is transferred from the pile to the surrounding via convection.

The profiles of concentration of oxygen during composting are shown in Figure 2(b). Initially, the concentration of oxygen decreases gradually because of the oxygen consumption in the cellulose oxidation. The decrease of profiles of oxygen concentration at the pile height of 0.4 m (point P, refer to Figure 1(a)) is more significant than the one at height of $2.15 \mathrm{~m}$ (point Q, refer to Figure 1(a)), in line with the higher temperature profiles at the pile height of $0.4 \mathrm{~m}$. At the onset of significant self-heating $\left(46^{\text {th }}\right.$ week), the concentration reduces significantly. This could be due to the cellulose oxidation rate, which increases tremendously during this period, as discussed above. At compost pile height of $2.15 \mathrm{~m}$, after the self-heating, the concentration of oxygen increases to approach ambient oxygen concentration. This is in line with the boundary condition of the mass balance of oxygen where at the upper surface of the pile, the concentration of oxygen is assumed to be equal with the ambient concentration of oxygen. Nevertheless, this does not happen to the oxygen concentration at the pile height of $0.4 \mathrm{~m}$ due to its location closer to the impermeable bottom pile.

Figure 2(c) indicates the profiles of moisture content during composting. The moisture content at the pile height of $2.15 \mathrm{~m}$ reduces from 3.5 to $2.9 \mathrm{~kg}$ water $/ \mathrm{kg}$ dry solids in the first 46 weeks. As a result of the temperature jump during the self-heating, the moisture content reduces and continues to decrease to approach the equilibrium moisture content. It appears that during 
composting, the moisture evaporates from the surface of solid matrix to the void space inside the compost piles. This transfer is described well by the reaction engineering approach (REA). The capability of the REA follows its applicability to represent the moisture transfer during selfheating of spray dried food powders (Chong and Chen, 1999). The profiles of moisture content at the pile height of $0.4 \mathrm{~m}$ are higher than those at the height of $2.15 \mathrm{~m}$, which could be because of its location, which is close to the bottom of the pile where no moisture transfer is allowed. At the upper surface of the pile, the moisture transfers to the ambient by convection.

The profiles of concentration of water vapor are shown in Figure 2(d). The profiles at the pile height of $0.4 \mathrm{~m}$ and $2.15 \mathrm{~m}$ are similar. At the beginning of composting, a slight increase in the concentration of water vapor is observed in agreement with the increase in temperatures and decrease in moisture content. At the compost pile height of $2.15 \mathrm{~m}$, after $46^{\text {th }}$ week of composting, the concentration of water vapor increases to $4.7 \mathrm{~kg} / \mathrm{m}^{3}$ corresponding well to the temperature jump. The profile is also reasonable since the moisture content decreases significantly at this period (Figure 6). Following this, the concentration of water vapor is decreased, which may be due to the low evaporation rate from the solid matrix to the void space because of the depletion of moisture content inside the piles. The concentration of water vapor at the height of $0.4 \mathrm{~m}$ is higher than that at the height of $2.15 \mathrm{~m}$, which is probably because of more enhanced evaporation rate at pile height of $0.4 \mathrm{~m}$ as a result of the higher temperature.

\subsection{The spatial profiles of temperature, concentration of oxygen, moisture content and concentration of water vapor}


The spatial profiles of temperature during composting are shown in Figure 3. Figure 3(a) indicates the spatial profiles after 46 weeks of composting (at onset of self-heating). The maximum temperature is achieved at the middle-bottom of the piles. It appears that this is the location of hot-spot location where the very large heat generated $\left(18946 \mathrm{~W} / \mathrm{m}^{3}\right)$ is not balanced by the heat removed. The temperature gradient inside the compost piles is relatively large in agreement with the low thermal conductivity of the compost. The temperature decreases towards the upper-surface of the piles because at the upper-surface of the piles, the heat is transferred to the ambient via convection. Generally, the temperature of the pile base is higher than that at the upper part due to the insulation boundary conditions implemented at the pile base. It seems that the heat liberated by exothermic cellulose oxidation and microorganisms growth to accumulate at this position. The spatial profiles of temperature after 46 weeks composting are shown in Figure 3(b). The temperature at $100^{\text {th }}$ week is lower than that at $46^{\text {th }}$ week which may be because of the decrease of the oxidation rate. No hot spot is noticed at this period. In addition, generally the temperature is more uniform that that at $46^{\text {th }}$ week which is possibly due to the lower temperature.

Figure 4(a) indicates the spatial profiles of concentration of oxygen after 46 weeks of composting. In agreement with the highest temperature at the middle-bottom of the pile, the lowest concentration of oxygen is located at this position. It appears that the highest oxidation reaction rate $\left(8.038 \times 10^{-6} \mathrm{~kg} / \mathrm{m}^{3} . \mathrm{s}\right)$ occurs at this location. In line with the temperature hot spot at this period, the gradient of concentration of oxygen is relatively large. The concentration of oxygen gradually increases towards the upper surface of the piles. This is reasonable since the upper surface is in contact with the ambient. The ambient concentration of oxygen is also 
imposed at the upper surface of the piles. The spatial profiles at $100^{\text {th }}$ week are shown in Figure 4(b). Compared to Figure 4(a), more uniform distribution of concentration of oxygen is observed in this period. This seems to be in line with the low concentration of oxygen at this period due to the depletion of oxygen inside the piles after the onset of self-heating.

The predicted spatial profiles of moisture content inside the piles are shown in Figures 5(a) and 5(b). Figure 5(a) shows the profiles of moisture content after 46 weeks of composting. The lowest moisture content is located at near the upper surface and the middle-bottom of the compost pile. This is reasonable since at the upper surface, the moisture is transferred to the surrounding via convection. For the middle-bottom, the high temperature at this location (Figure 3(a)) seems to be responsible for enhancing the local evaporation rate. At the left and right corner of the piles, the moisture content is higher than that at the upper surface which may be related to the impermeable boundary conditions at the pile base. At $100^{\text {th }}$ week, the moisture content is much lower than that at the $46^{\text {th }}$ week since the equilibrium condition is approached. In line with this, the distribution of moisture content inside the pile is lower than that at the $46^{\text {th }}$ week. This is also in agreement with the low distribution of temperature (Figure 3(b)) and concentration of oxygen (Figure 4(b)).

Figure 6(a) indicates the profiles of concentration of water vapor inside the piles after 46 weeks of composting. The maximum concentration of water vapor is located at the middlebottom of the piles which could be due to the increased local evaporation rate as a result of temperature increase. The enhanced local evaporation rate seems also to be coupled with the impermeable boundary condition at the pile base This matches well with the highest temperature 
(Figure 3(a)) as well the lowest moisture content (Figure 5(a)) at this location. Above the middlebottom, the concentration of water vapor is relatively low which seems to be due to the relative low moisture content in this area combined with the convective transport of water vapor to the surrounding. The profiles of concentration of water vapor inside the piles at $100^{\text {th }}$ week are shown in Figure 6(b). The concentration of water vapor at this period is lower than that at $46^{\text {th }}$ week which could be related to the lower moisture content at this period. The concentration of water vapor at the upper surface is slightly lower than that at the center of pile. This is reasonable since at the upper surface, the diffusive water vapor is balanced with the convective water vapor to the ambient. Nevertheless, the gradient of concentration of water vapor at this stage is lower than that at the $46^{\text {th }}$ week. Similar phenomena are also observed for the temperature, concentration of oxygen and moisture content as highlighted above.

Based on the above discussions, the new model is able to describe the profiles of concentration of oxygen, temperature, moisture content and concentration of water vapor. While the model matches well with the experimental data, the complex interrelationships between these variables are well explained by the model. By application of the reaction engineering approach (REA), the reasonable profiles of moisture content and concentration of water vapor are generated. These profiles help to comprehend better the transport phenomena inside the piles. The accuracy of the model also indicates that the REA is an alternative model to describe the local evaporation/condensation rate inside porous materials undergoing heat and mass transfer processes at elevated temperature coupled with the chemical and biological reactions. The new model can be used to assist in prediction of the extent of self-heating during composting as well 
as explore composting conditions (geometry and configuration of piles, air conditions) to avoid the self-heating.

\section{Conclusions}

Composting that induces elevated temperature may lead to self-heating. In this paper, a new mathematical model has been assembled to predict the self-heating. The model consists of a set of equations of conservation in which the reaction engineering approach is employed to model the local evaporation rate. The model overall predicts intuitively correct profiles of temperature, moisture content, concentration of oxygen and water vapor. A comparison between the experimental and simulated temperature-time profiles shows the good promise. The model has helped to visualize the transport phenomena during composting. Sludge bio-drying using this system will be investigated in the near future. 
Appendix A. A Brief review of the reaction engineering approach (REA) (Chen and Putranto, 2013)

By using the REA, the mass balance of water during heat and mass transfer processes can be expressed as (Chen and Xie, 1997; Chen, 2008):

$$
m_{s} \frac{d \bar{X}}{d t}=-h_{m} A\left[\exp \left(\frac{-\Delta E_{v}}{R T_{s}}\right) \rho_{v, s a t}\left(T_{s}\right)-\rho_{v, b}\right]
$$

where $\bar{X}$ is the average moisture content on dry basis, $h_{m}$ is the mass transfer coefficient $\left(\mathrm{m}^{-1}{ }^{-1}\right)$, $A$ is the surface area $\left(\mathrm{m}^{2}\right), \Delta E_{v}$ is the activation energy $\left(\mathrm{J} \cdot \mathrm{mol}^{-1}\right), T_{s}$ is the sample temperature $(\mathrm{K})$, $m_{s}$ is the dried mass of sample $(\mathrm{kg}), \rho_{v, \text { sat }}$ is the saturated water vapor concentration $\left(\mathrm{kg} \cdot \mathrm{m}^{-3}\right)$ and $\rho_{v, b}$ is the concentration of water vapor in drying medium $\left(\mathrm{kg} \cdot \mathrm{m}^{-3}\right)$.

Equation (A1) indicates that the REA is expressed in first order ordinary differential equation with respect to time. Equation (1) is the core of the reaction engineering approach, further called as the lumped reaction engineering approach (L-REA). The L-REA does not assume uniform moisture content but it evaluates average moisture content of the samples during drying.

The activation energy $\left(\Delta E_{v}\right)$ is determined experimentally by placing the parameters required for equation (A1) in its rearranged form:

$$
\Delta E_{v}=-R T_{s} \ln \left[\frac{-m_{s} \frac{d \bar{X}}{d t} \frac{1}{h_{m} A}+\rho_{v, b}}{\rho_{v, s a t}}\right]
$$

where $d \bar{X} / d t$ is experimentally determined. Besides the average moisture content, the surface area, temperature and mass transfer coefficient need to be measured or known. 
The dependence of activation energy on average moisture content on a dry basis $(\bar{X})$ can be normalized as:

$$
\frac{\Delta E_{v}}{\Delta E_{v, b}}=f\left(\bar{X}-X_{b}\right)
$$

wheref is a function of water content difference, $\Delta E_{v, b}$ is the 'equilibrium' activation energy representing the maximum $\Delta E_{v}$ determined by the relative humidity and temperature of the drying air:

$$
\Delta E_{v, b}=-R T_{b} \ln \left(R H_{b}\right)
$$

$R H_{b}$ is the relative humidity of drying air and $T_{b}$ is the drying air temperature $(\mathrm{K})$.

In order to generate the relative activation energy $\left(\Delta E_{v} / \Delta E_{v, b}\right)$ shown by equation (A4), the activation energy $\left(\Delta E_{v}\right)$ can be evaluated by equation (A2) from one accurate drying experiment. So far, the experiments conducted to generate the relationship (equation (A3)) generally employed fairly dry air so the relationship covers a complete range of water content difference $\left(\bar{X}-X_{b}\right)$ while $X_{b}$ in the experiments for generating REA parameters is set to be very small value.

The activation energy is divided by the equilibrium activation energy $\left(\Delta E_{v, b}\right)$ indicated by equation (A4) to yield the relative activation energy during drying. This is a normalization process. For similar drying condition and initial water content, it is possible to obtain the necessary REA parameters (apart from the equilibrium isotherm), expressed in the relative activation energy $\left(\Delta E_{v} / \Delta E_{v, b}\right)$ as indicated in equation (A3) in one accurate drying experiment. 
The relative activation energy $\left(\Delta E_{v} / \Delta E_{v, b}\right)$ generated can then be used to project to other drying conditions provided the material has the same initial moisture content (Chen, 2008). 
Table 1. The thermo-physical properties of sewage sludge (Sidhu, Nelson and Chen, 2007; Moraga et al, 2009)

\begin{tabular}{|c|c|}
\hline Properties & Value \\
\hline $\mathrm{A}_{\mathrm{C}}\left(\mathrm{m}^{3} / \mathrm{kg} . \mathrm{s}\right)$ & $1.8 \times 10^{4}$ \\
\hline $\mathrm{A}_{1}\left(\mathrm{~m}^{3} / \mathrm{kg} . \mathrm{s}\right)$ & $2 \times 10^{6}$ \\
\hline $\mathrm{A}_{2}$ & $6.86 \times 10^{32}$ \\
\hline $\mathrm{E}_{\mathrm{c}}\left(\mathrm{J} \cdot \mathrm{mol}^{-1}\right)$ & $1.1 \times 10^{5}$ \\
\hline $\mathrm{E}_{1}\left(\mathrm{~J} \cdot \mathrm{mol}^{-1}\right)$ & $1 \times 10^{5}$ \\
\hline $\mathrm{E}_{2}\left(\mathrm{~J} \cdot \mathrm{mol}^{-1}\right)$ & $2 \times 10^{5}$ \\
\hline $\mathrm{Q}_{\mathrm{b}}\left(\mathrm{J} \cdot \mathrm{kg}^{-1}\right)$ & $7.66 \times 10^{6}$ \\
\hline $\mathrm{Q}_{\mathrm{c}}\left(\mathrm{J} \cdot \mathrm{kg}^{-1}\right)$ & $5.5 \times 10^{9}$ \\
\hline$\rho_{\mathrm{b}}\left(\mathrm{kg} \cdot \mathrm{m}^{-3}\right)$ & 575 \\
\hline$\rho_{\mathrm{c}}\left(\mathrm{kg} \cdot \mathrm{m}^{-3}\right)$ & 1150 \\
\hline
\end{tabular}




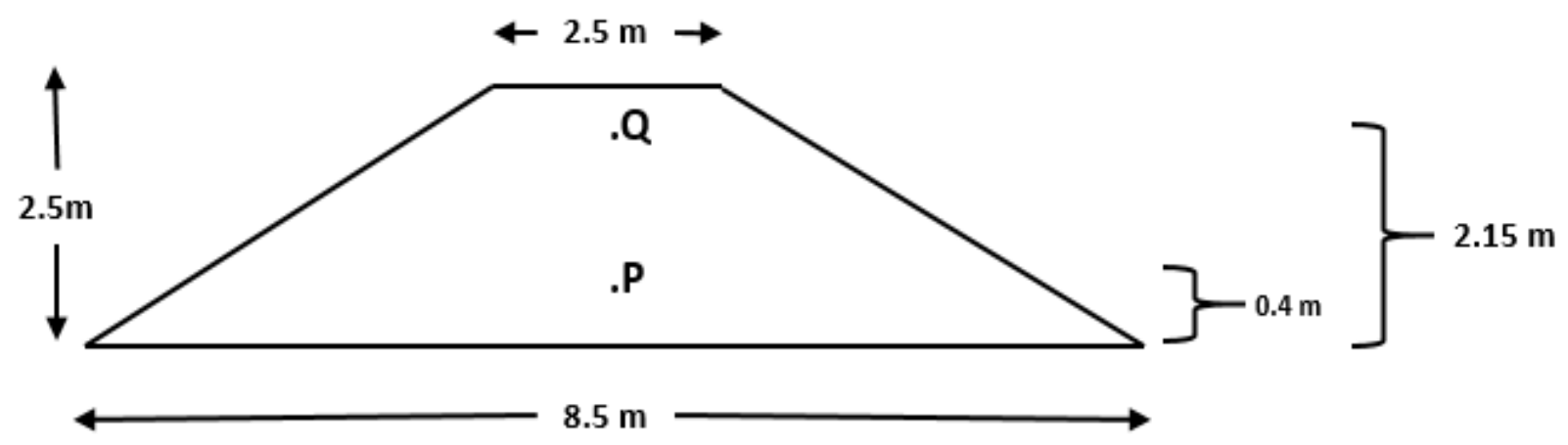

Figure 1(a). The geometry of compost piles

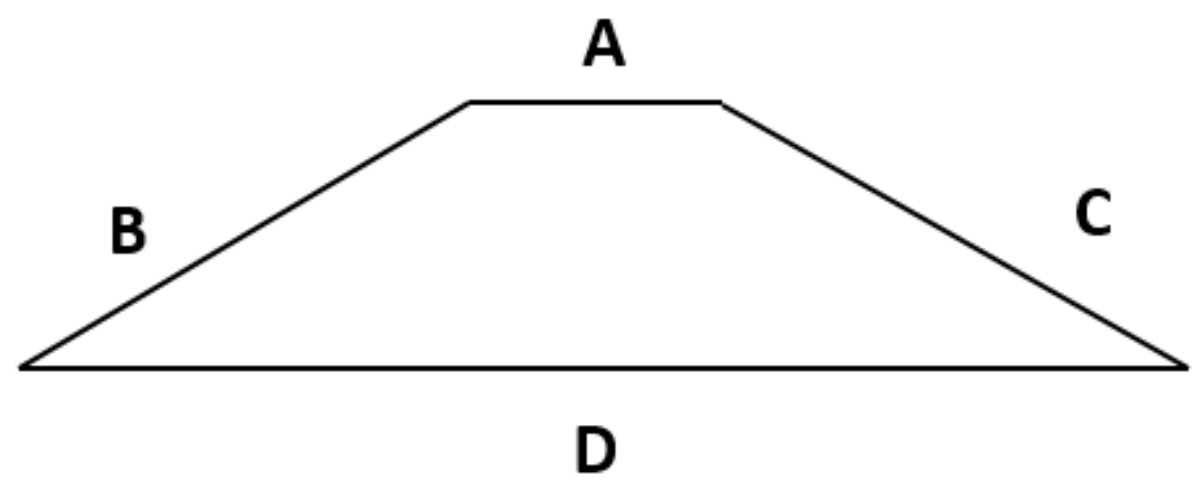

Figure 1(b). The boundary conditions of the modeling 


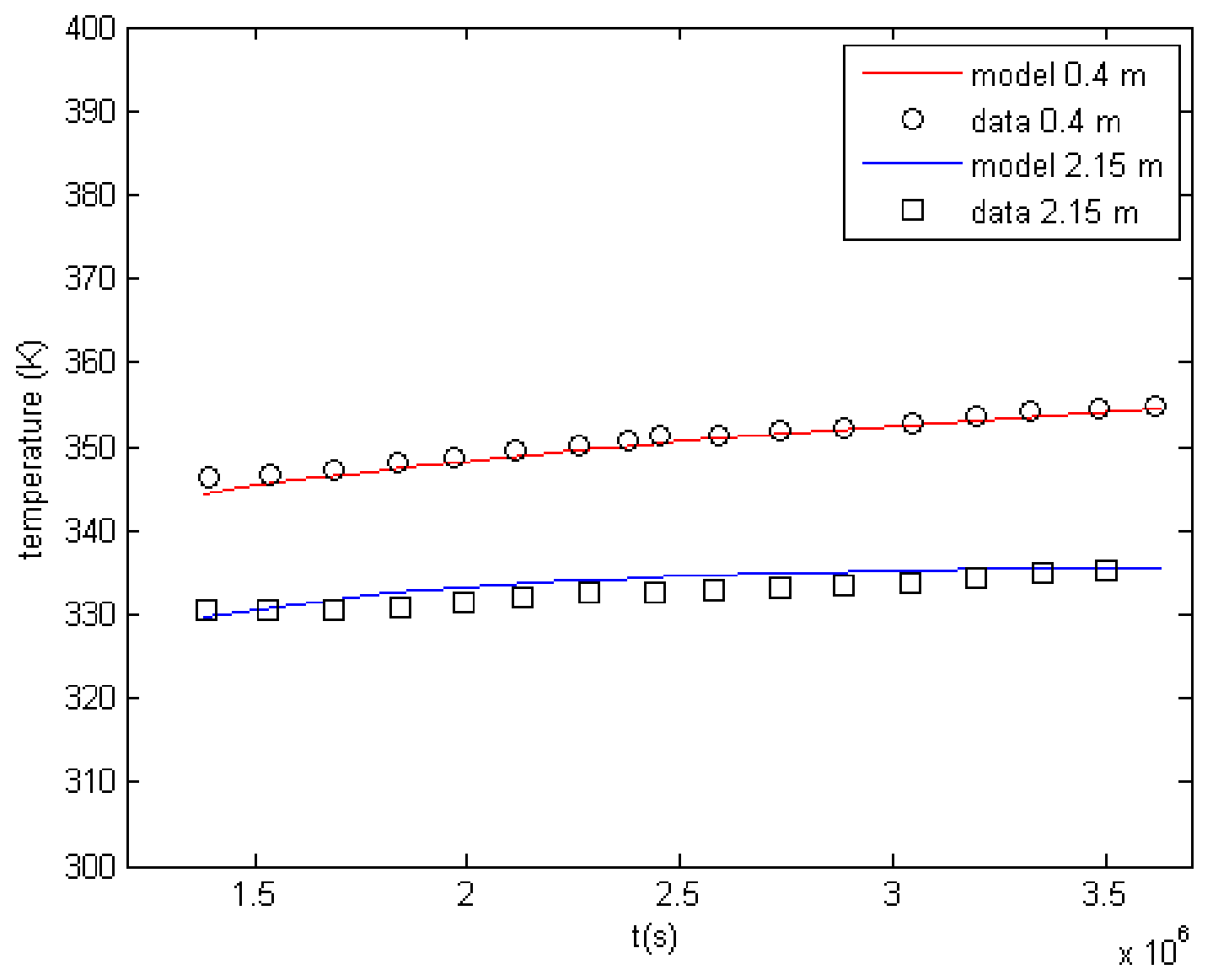

Figure 1(c). The validated temperature profiles during composting (using boundary condition of adiabatic at the pile bottom) 


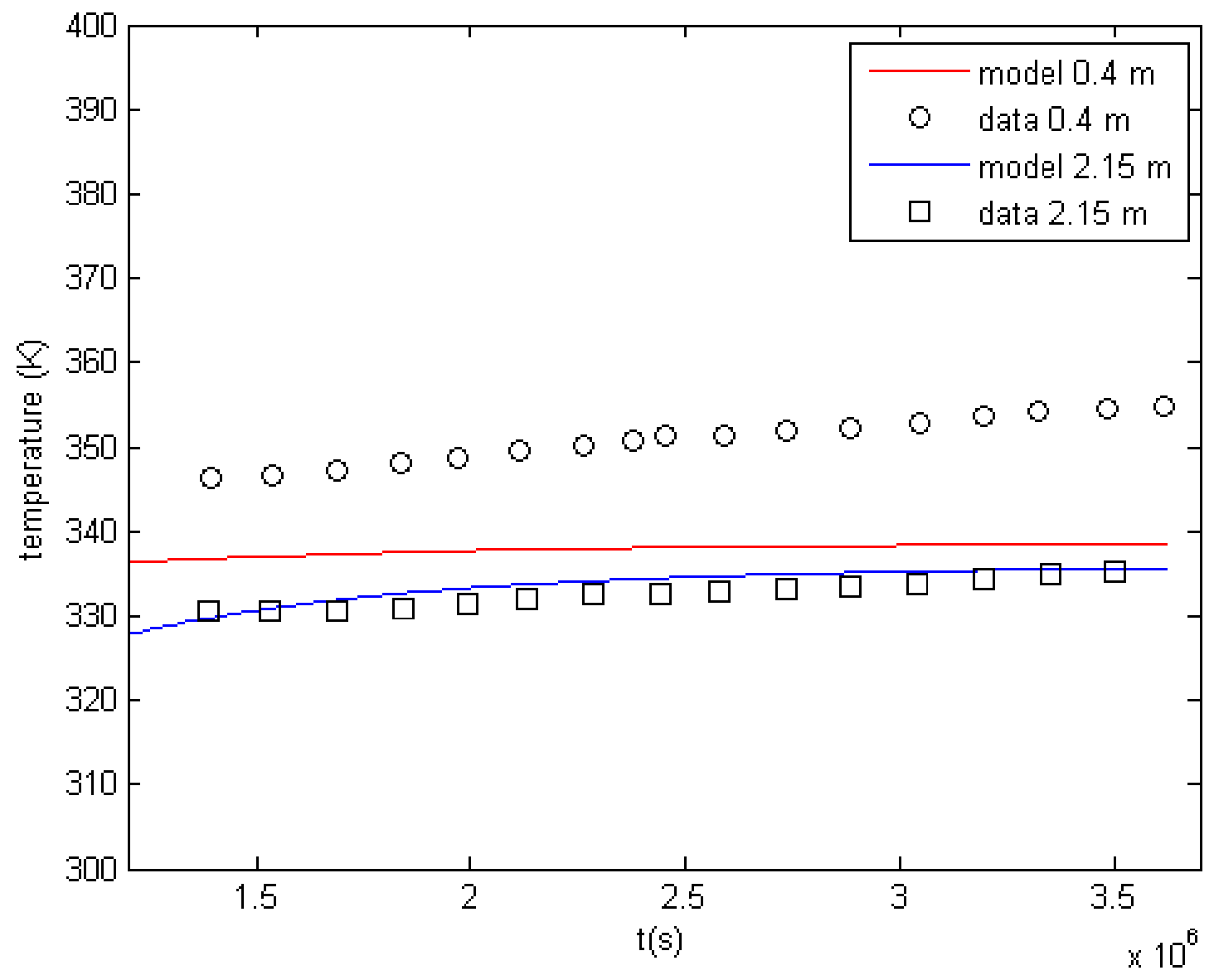

Figure 1(d). The validated temperature profiles during composting (using boundary condition of ambient temperature at the pile bottom) 


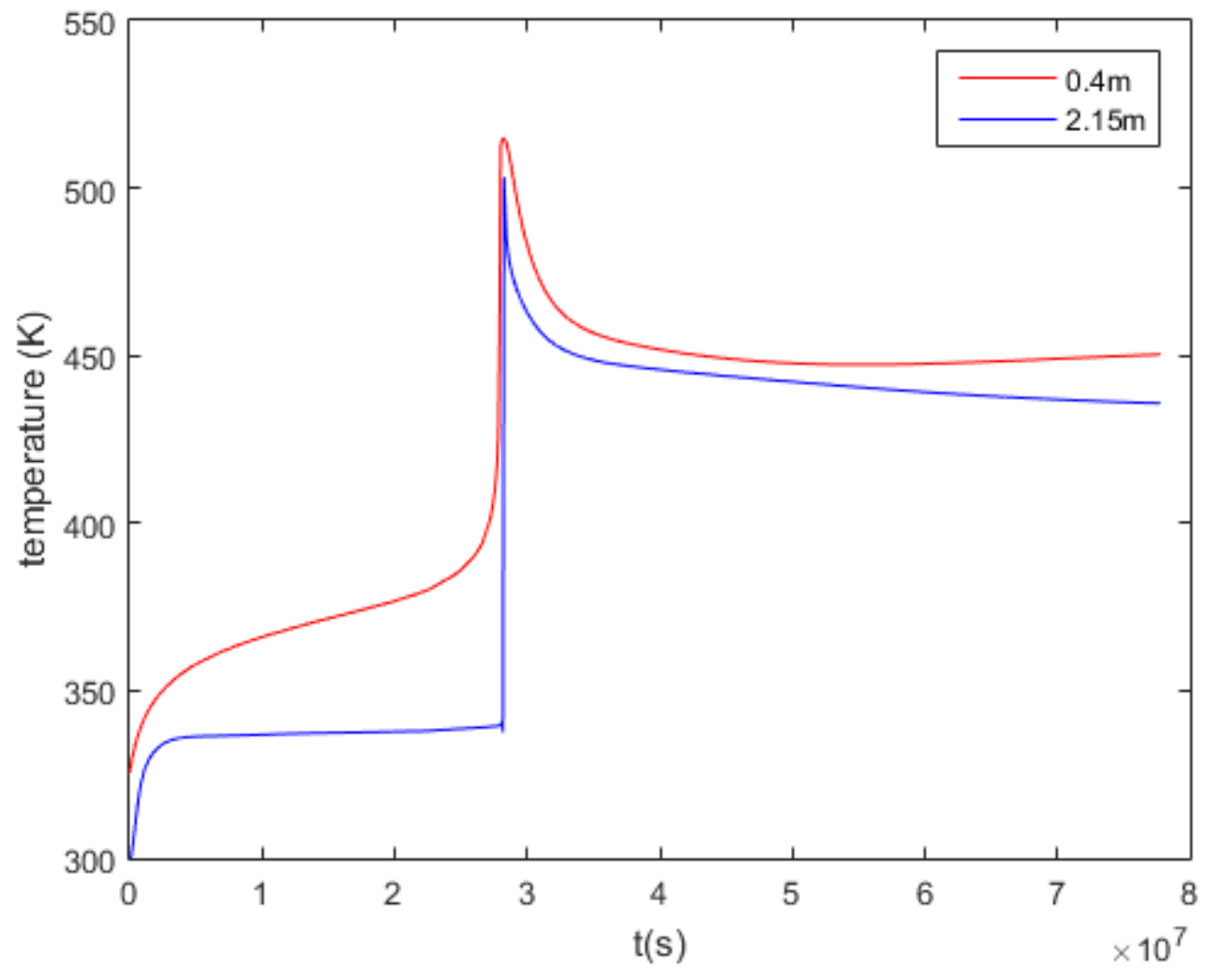

Figure 2(a).The predicted temporal profiles of temperature during composting 


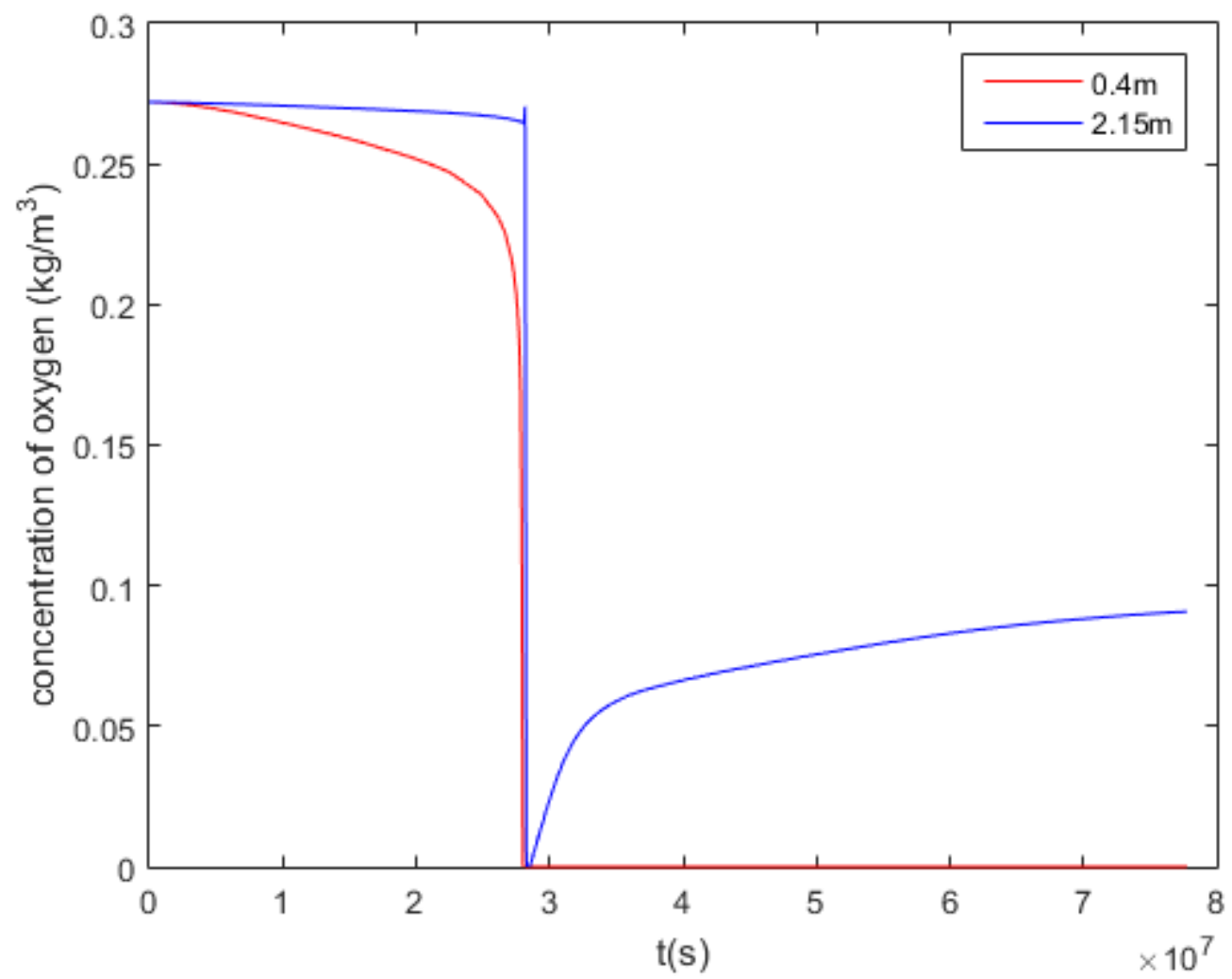

Figure 2(b). The predicted temporal profiles of concentration of oxygen during composting 


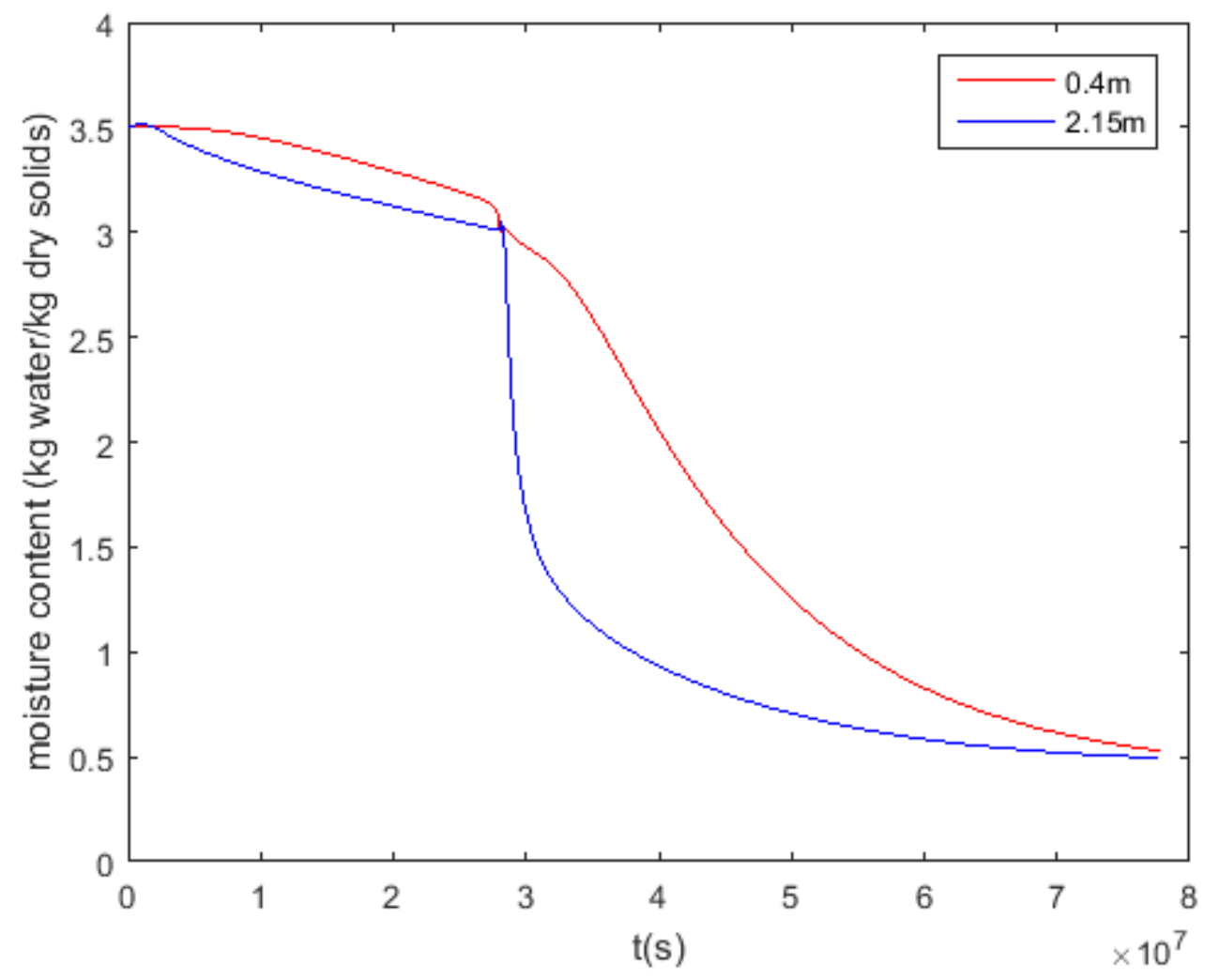

Figure 2(c). The predicted temporal profiles of moisture content during composting 


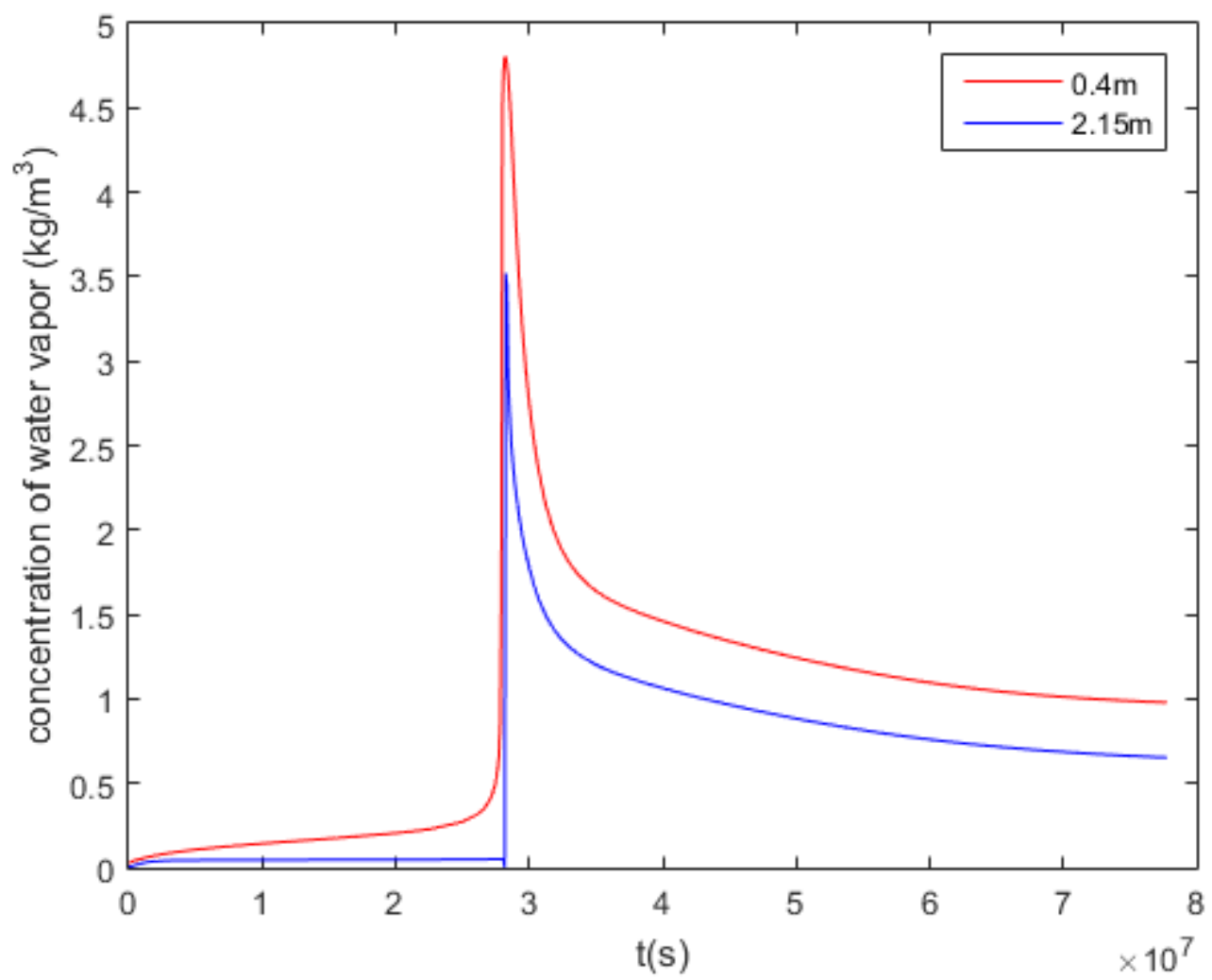

Figure 2(d). The predicted temporal profiles of concentration of water vapor during composting 


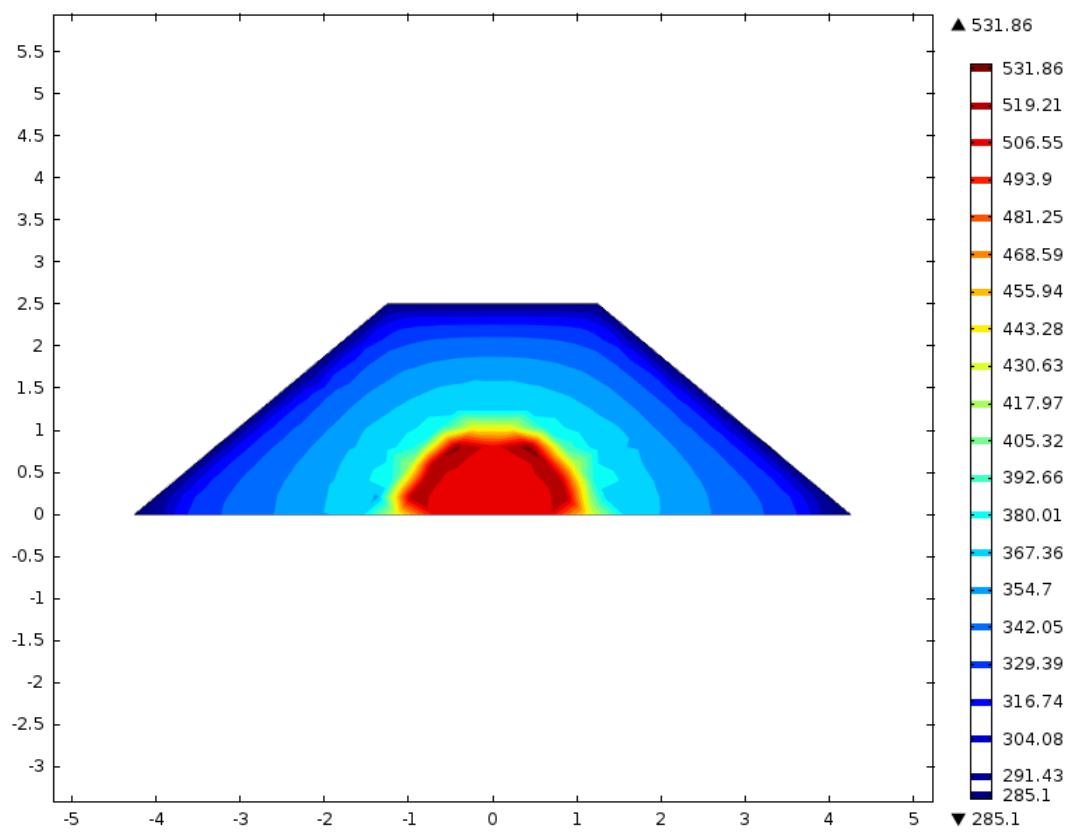

(a)

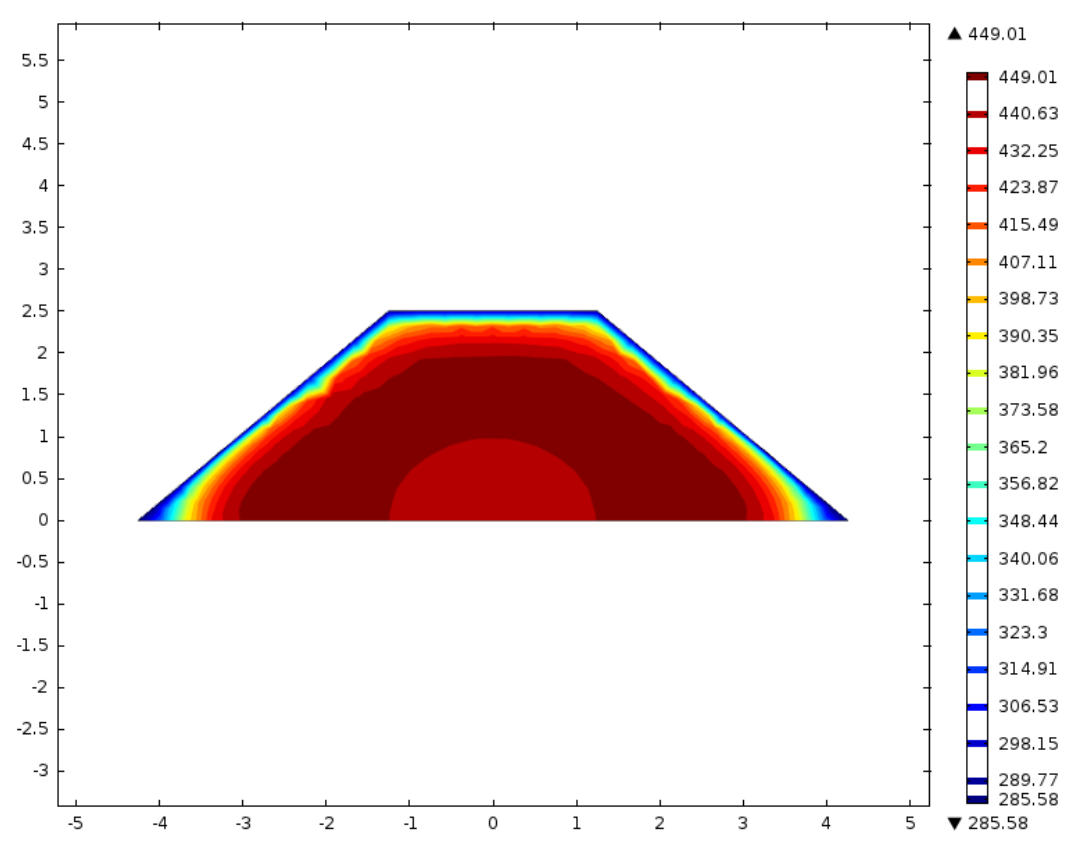

(b)

Figure 3. The spatial profiles of temperature (K) during composting (a) after 46 weeks (b) after 100 weeks 


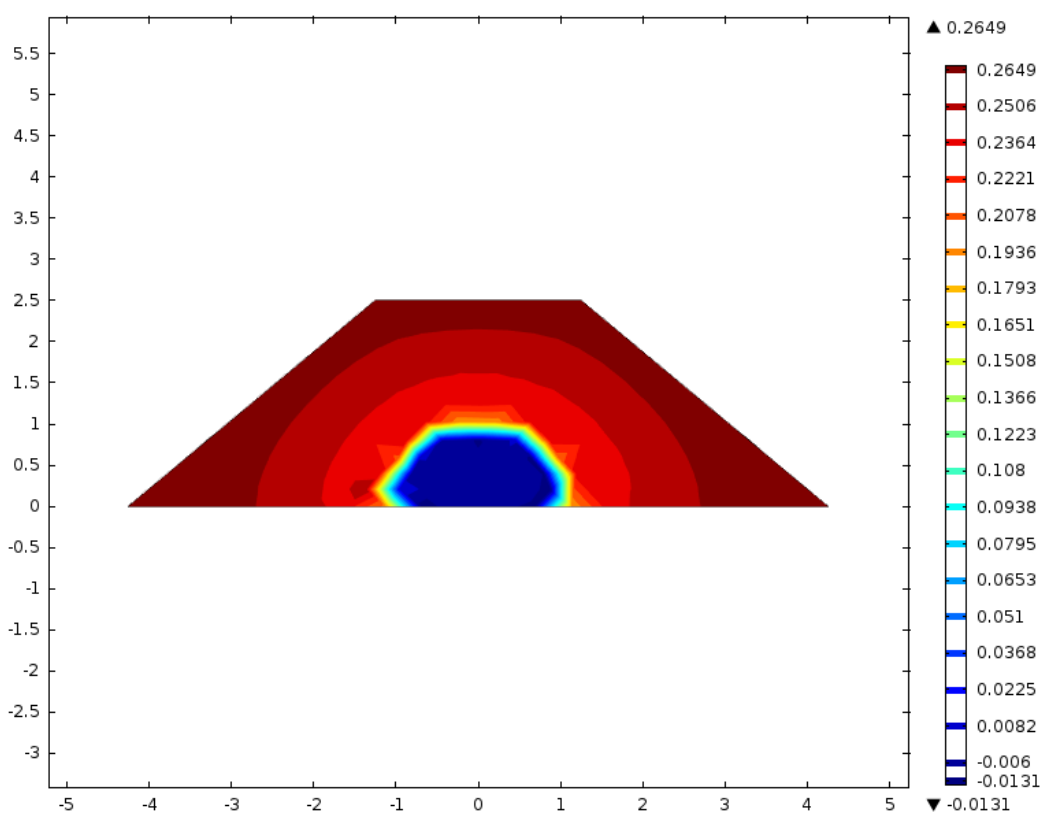

(a)

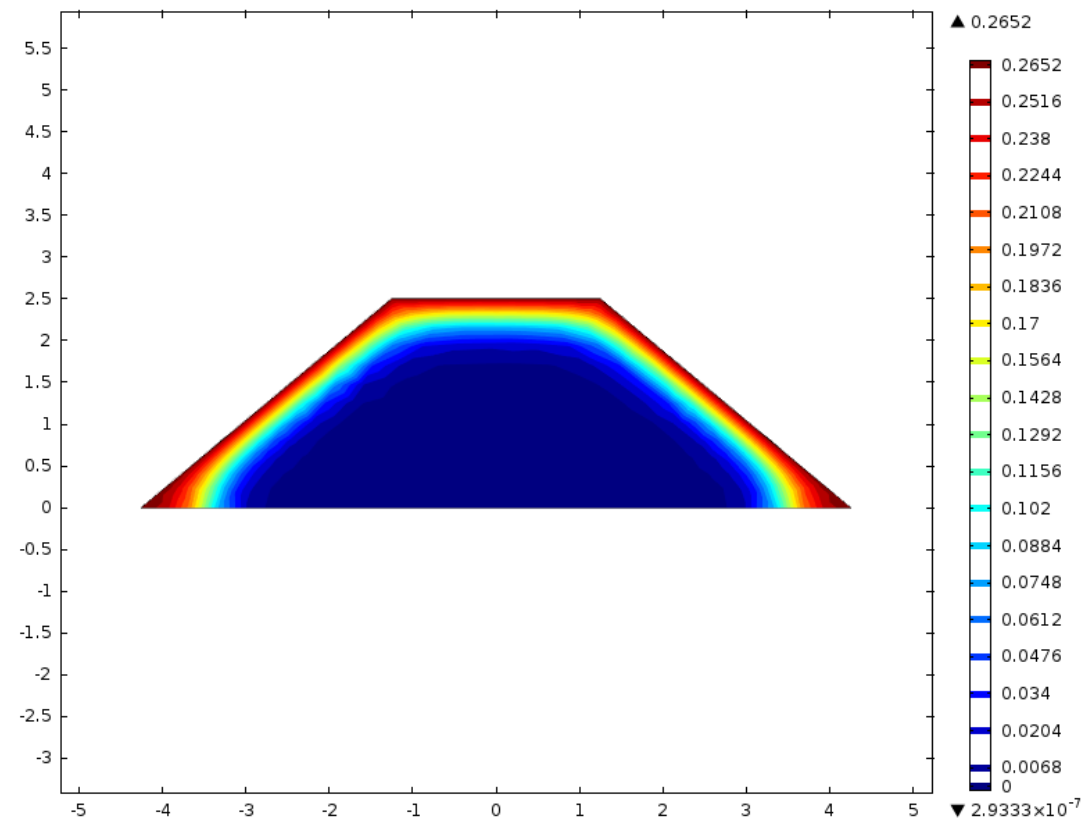

(b)

Figure 4. The spatial profiles of concentration of oxygen $\left(\mathrm{kg} / \mathrm{m}^{3}\right)$ during composting (a) after 46 weeks (b) after 100 weeks 


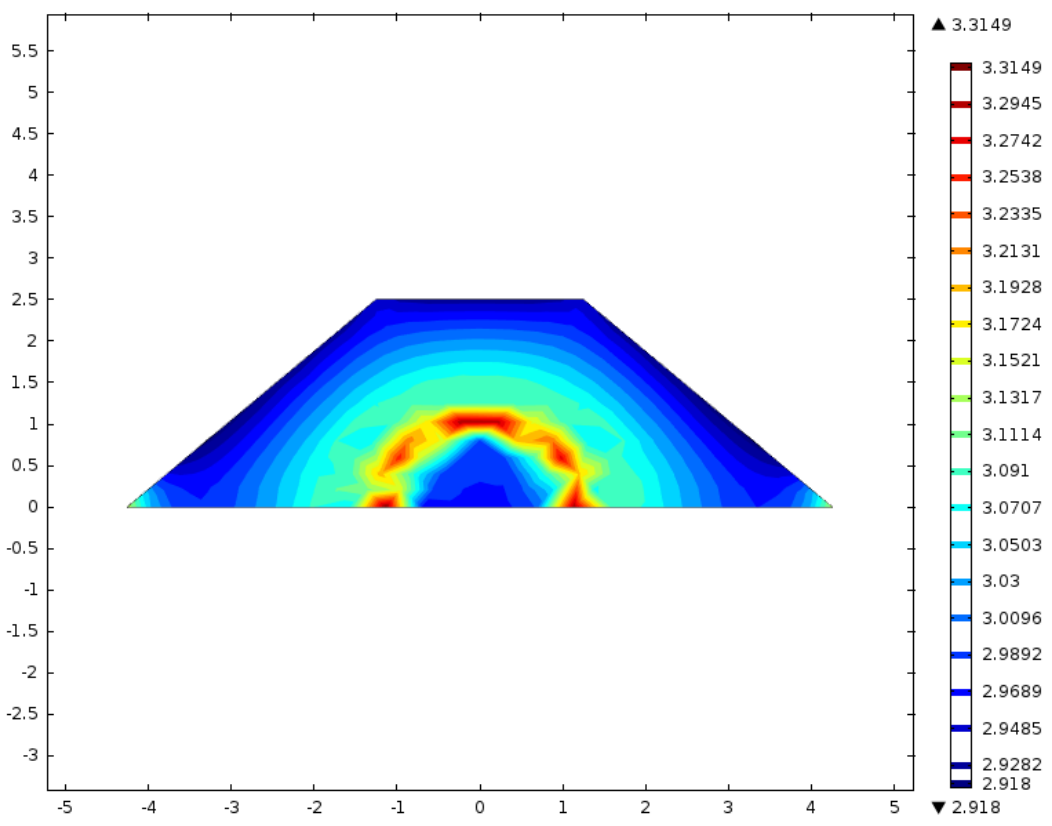

(a)

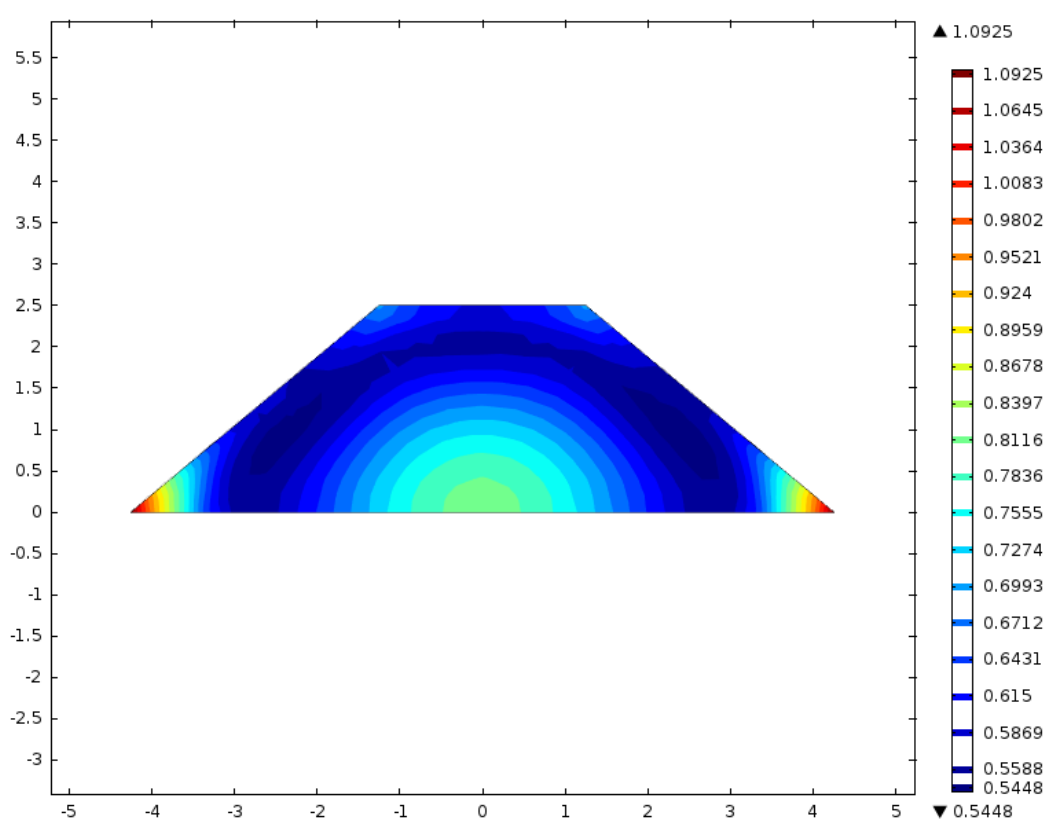

(b)

Figure 5. The spatial profiles of moisture content during composting (kg water/kg dry solids)

(a) after 46 weeks (b) after 100 weeks 


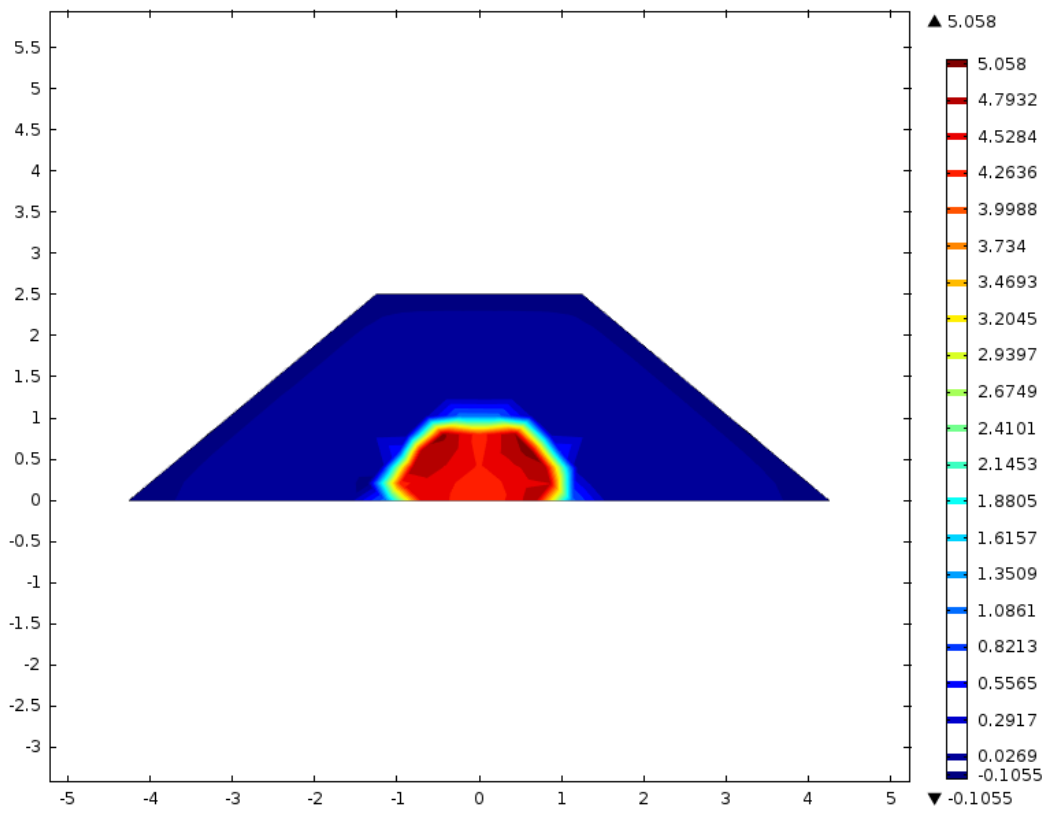

(a)

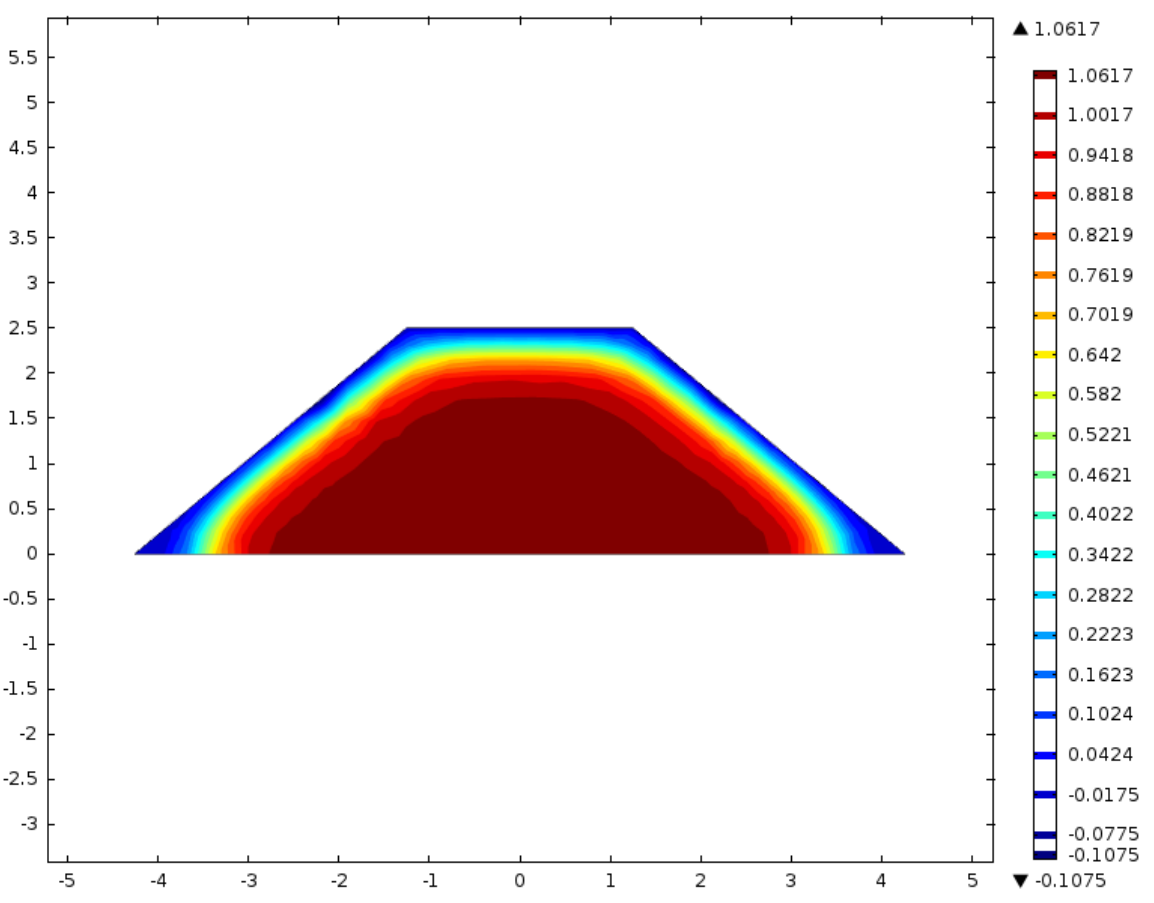

(b)

Figure 6. The spatial profiles of concentration of water vapor during composting (kg water $/ \mathbf{m}^{3}$ )

(a) after 46 weeks (b) after 100 weeks 


\section{References}

1. Ahn, H.K, Richard, T.L., Glanville, T.D., 2008. Laboratory determination of compost physical parameters for modeling of airflow characteristics. Waste Management 28, 660-670.

2. Bowes, P. C., 1984, Self-heating: Evaluating and Controlling the Hazards. Elsevier, Amsterdam.

3. Chen, X. D., Chong, L.V., 1998. Several important issues related to the crossingpoint temperature (CPT) method for measuring self-ignition kinetics of combustible solids. TransIChemE Part B 76, 90-93.

4. Chen, X.D., 1998. On the fundamentals of diffusive self-heating in water containing combustible materials. Chem Eng Proc 37 (1998) 367-378.

5. Chen, X.D., Mitchell, D.A., 1996. Start-up strategies for self-heating and efficient growth in stirred bioreactors for solid state fermentation. In:Weiss, G. (Ed.), CHEMECA 1996, 24th Australian and New Zealand Chemical Engineering Conference, vol. 4. The Institute of Engineers, 111-116. ISBN 0-85825-658-4.

6. Chen, X.D., Putranto, A., 2013. Modeling Drying Processes: A Reaction Engineering Approach. Cambridge University Press, U.K.

7. Chen, X.D., Sidhu, H., Nelson, M., 2013. A linear relationship between dimensionless crossing-point-temperature and Frank-Kamenetskii reactivity parameter in self-heating test at infinite Biot number for slab geometry. Fire Safety Journal 6, 138-143.

8. Cornell Waste $\quad$ Management 1996. http://cwmi.css.cornell.edu/composting.htm 
9. Frank-Kamenetskii, D. A., 1939, Calculation of thermal explosion limits, Acta Phys Chin, URSS 10, 365-370.

10. Gray, B. F., Griffiths, J. F. and Hasko, S. M., 1991, Spontaneous ignition hazards in stockpiles of cellulosic materials: criteria for safe storage, J. Chem Techn and Biotech 34A, 453-463.

11. Gray, B.F., Sexton, M.J., Halliburton, B., Macaskill, C., 2002. Wetting-induced ignition in cellulosic materials. Fire Safety Journal 37, 465-479.

12. Jiang, J., Liu, X., Huang, Y., Huang, H., 2015. Inoculation with nitrogen turnover bacterial agent appropriately increasing nitrogen and promoting maturity in pig manure composting. Waste Management 39, 78-85.

13. Liang, C., Das, K.C., McClendon, R.W., 2003. The influence of temperature and moisture contents regimes on the aerobic microbial activity of a biosolids composting blend. Biores Tech 86, 131-137.

14. Lin, Y.P., Huang, G.H., Lu, H.W. and He, L., 2008, Modelling of substrate degradation and oxygen consumption in waste composting processes. Waste Management 28, 1375-1385.

15. Luangwilai, T. Sidhu, H.S., Nelson, M.I., Chen, X.D., 2010. Modelling air flow and ambient temperature effects on the biological self-heating of compost piles. AsiaPacific J of Chem Eng 5, 609-618.

16. Moraga, N.A., Corvalan, F., Escudey, M., Arias, A., Zambra, C.E., 2009. Unsteady 2D coupled heat and mass transfer in porous media with biological and chemical heat generations. Int J Heat Mass Transf 52, 5841-5848. 
17. Meng, L., Li, W., Zhang, S., Wu, C., Lv, L., 2017. Feasibility of co-composting of sewage sludge, spent mushroom substrate and wheat straw. Bioresource Technology 226 (2017) 39-45.

18. Meng, L., Li, W., Zhang, S., Wu, C., Jiang, W., Sha, C., 2016. Effect of different extra carbon sources on nitrogen loss control andthe change of bacterial populations in sewage sludge composting. Ecological Engineering 94, 238-243.

19. Nakayama, A., Nakasaki, K., Kuwahara, F., Sano, Y., 2007. A lumped parameter heat transfer analysis for composting processes with aeration. Transactions of theASME 129, 902-906.

20. Nelson, M., Marchant, T.R., Wake, G.C., Balakrishnan, E., Chen, X.D., 2007. Selfheating in compost piles due to biological effects. Chem Eng Sci 62, 4612 - 4619.

21. Nelson, V. L., Crowe, T. G., Shah, M. A., Watson, L. G., 2006. Temperature and turning energy of composting feedlot manure at different moisture contents in southern Alberta. Canadian Biosyst Eng 48, 631-638.

22. Putranto, A., Chen, X.D., 2013 ${ }^{\mathrm{a}}$. Spatial reaction engineering approach (S-REA) as an alternative for non-equilibrium multiphase mass transfer model for drying of food and biological materials. AIChE J 59, 55-67.

23. Putranto, A., Chen, X.D., 2013 ${ }^{\mathrm{b}}$. Multiphase modeling of intermittent drying using the spatial reaction engineering approach (S-REA). Chem Eng Proc 70, 169-183.

24. Putranto, A., Chen, X.D., 2014 . Examining the suitability of the reaction engineering approach (REA) to modeling localevaporation/condensation rates of materials with various thicknesses. Drying Techn 32, 208-221. 
25. Putranto, A., Chen, X.D., 2014 . A simple and effective model for modeling of convective drying of sewage sludge: the reaction engineering approach (REA). Procedia Chem 9, 77-87.

26. Putranto, A., Chen, X.D., 2015 a . Spatial reaction engineering approach (S-REA): an effective approach to model drying, baking and water vapor sorption process. Chem Eng Res Des 101, 135-145.

27. Putranto, A., Chen, X.D., 2015 ${ }^{\mathrm{b}}$. Bread baking and its color kinetics modeled by the spatial reaction engineering approach (S-REA). Food Res Int 71, 58-67.

28. Putranto, A., Chen, X.D., 2015 . An assessment on modeling drying processes: Equilibrium multiphase model and the spatial reaction engineering approach. Chem Eng Res Des 94, 660-672.

29. Putranto, A., Chen, X.D., Devahastin, S., Xiao, Z., Webley, P.A., 2011 ${ }^{\text {b }}$. Application of the reaction engineering approach (REA) to model intermittent drying under timevarying humidity and temperature. Chem Eng Sci 66, 2149-2156.

30. Putranto, A., Chen, X.D., Xiao, Z., Webley, P.A., 2011 a . Mathematical modeling of convective and intermittent drying of rice and coffee using the reaction engineering approach (REA). J Food Eng 105, 306-311.

31. Rynk, R., 1992. On-farm Composting Handbook

32. Rynk, R., 2000, Fires at composting facilities. BioCycle Magazine 41, 54-58.

33. Sexton, M.C., Macaskill, C., Gray, B.F., 2001. Self-heating and drying in twodimensional bagasse piles. Combustion Theory Modelling 5, 517-536.

34. Sidhu, H.S, Nelson, M.I., Chen, X.D, 2007. A simple spatial model for self-heating of compost piles. ANZIAM Journal 48, C135-150. 
35. Velis, C.A., Longhurst, P.J., Drew, G.H., Smith, R., Pollard, S.J.T., 2009. Biodrying for mechanical-biological treatment of wastes: A review of process science and engineering. Biores Tech 100, 2747-2761.

36. Villegas, M., Huilinir. C., 2014. Biodrying of sewage sludge: Kinetics of volatile solids degradation under different initial moisture contents and air-flow rates. Biores Tech 174, 33-41.

37. Winkler, M.K.H., Bennenbroek, M.H.„,Horstink, F.H., van Loosdrecht, M.C.M., van de Pol, G.J., 2013. The biodrying concept: An innovative technology creating energy from sewage sludge. Biores Tech 147, 124-129.

38. Wang, X., Cui, H., Shi, J., Zhao, X., Zhao, Y., Wei, Z., 2015. Relationship between bacterial diversity and environmental parameters during composting of different raw materials. Biores Tech 198, 395-402.

39. Yuan, J., Chadwick, D., Zhang, D., Li, G., Chen, S., Luo, W., Du, L., He, S., Peng, S., 2016. Effects of aeration rate on maturity and gaseous emissions during sewage sludge composting. Waste Management 56, 403-410.

40. Zambra, C.E., Rosales, C., Moraga, N.O., Ragazzi, M., 2011. Self-heating in a bioreactor: Coupling of heat and mass transfer with turbulent convection. Int J Heat Mass Transf 54, 5077-5086. 